\title{
Hemimaxillofacial Dysplasia/Segmental Odontomaxillary Dysplasia (HD/SOD): An Updated Review of 65 Cases and Report of an Unusual New Case
}

\author{
Kıvanç Kamburoğlư ${ }^{1 *}$, Nurver Karslı ${ }^{2}$ Ayşegül Köklü² and Ömer Günhan ${ }^{3}$ \\ ${ }^{1}$ Department of Dentomaxillofacial Radiology, Faculty of Dentistry, Ankara University, Turkey \\ ${ }^{2}$ Department of Orthodontics, Faculty of Dentistry, Ankara University, Turkey \\ ${ }^{3}$ Department of Pathology, TOBB University, Turkey
}

*Corresponding author: Kıvanç Kamburoğlu, Department of Dentomaxillofacial Radiology, Faculty of Dentistry, Ankara University, Ankara, Turkey, Tel: +903122965632, Fax: +903122123954

\begin{abstract}
Introduction: The aim of the present review was to analyze the literature and describe the clinical and radiographic features of HD-SOD. In addition, an unusual new case which was thought to be a subtle type of HD-SOD, involving a girl, was presented with detailed characteristics of HD-SOD. All HD-SOD cases published between 1987 and 2020, along with the present case, making a total of 66 cases, were evaluated according to criteria which included gender, age, and location of the lesion, clinical and radiological findings. Some of the previously reported cases lacked information regarding various criteria.

Clinical consequences: We have found that the lesion was discovered mainly in the 1st decade of life, and has a significant male predilection with a female-to-male ratio of 1:1.9. In all cases except one, the alveolar process of the maxilla was affected unilaterally, with gingival and bone enlargement and facial asymmetry being constant findings. Missing maxillary permanent premolars and skin manifestations such as; hypertrichosis and nevus are also common symptoms. Bone pattern was generally termed as vertically oriented, sclerotic, ill-defined, dense and granular radiopacity. Early recognition of $\mathrm{HD} / \mathrm{SOD}$ also requires appropriate referrals to colleagues and interdisciplinary team approach, thus patients with HD/SOD can gain access to specialist dental care, including orthodontics, prosthodontics, and oral surgery
\end{abstract}

\section{Keywords}

Segmental odontomaxillary dysplasia, Hemimaxillofacial dysplasia, Diagnosis

\section{Main Points}

- HD-SOD is detected at birth or childhood and characterized by unilateral enlargement of the alveolar process of maxilla in association with gingiva and teeth.

- We presented a unique mild case along with expansive literature review.

- New cases should include clinical, radiographic, histologic findings, follow-up reports and treatment protocols.

\section{Introduction}

Miles, et al. [1] in 1987 were the first to mention Hemimaxillofacial dysplasia (segmental odontomaxillary dysplasia) (HD-SOD) in a report of two cases. Since then, several authors have made noteworthy contributions to our knowledge concerning the disorder. It is a rare developmental and non-progressive abnormality of unknown etiology first recognized almost 30 years ago, and relevant data is incomplete. It is detected at birth or childhood and characterized by unilateral enlargement of the alveolar process of maxilla in association with gingiva and teeth. Radiographic appearance of the affected bone is sclerotic and often vertically oriented. Missing permanent premolars, tooth abnormalities, delayed eruption and displayed teeth are common findings. There are accompany-

Citation: Kamburoğlu K, Karslı N, Köklü A, Günhan O (2020) Hemimaxillofacial Dysplasia/Segmental Odontomaxillary Dysplasia (HD/SOD): An Updated Review of 65 Cases and Report of an Unusual New Case. Int J Oral Dent Health 6:122. doi.org/10.23937/2469-5734/1510122

Accepted: December 29, 2020: Published: December 31, 2020

Copyright: (c) 2020 Kamburoğlu K, et al. This is an open-access article distributed under the terms of the Creative Commons Attribution License, which permits unrestricted use, distribution, and reproduction in any medium, provided the original author and source are credited. 
ing manifestations, such as; facial asymmetry, hypertrichosis, nevus, erythema and hypopigmentation in the skin. Immature woven bone with irregular patterns and gingival hyperplasia are histologically common findings. Differential diagnosis includes hemifacial hyperplasia, monostatic fibrous dysplasia, and regional odontodysplasia [1-31].

\section{Case Presentation}

An 11-year-old girl with the chief complaint of ineffective chewing of food as a result of anterior open bite was referred to Ankara University, Department of Orthodontics in Turkey (Figure 1). Patient was asymptomatic and her medical history was non-contributory. An informed consent was received from the patient's
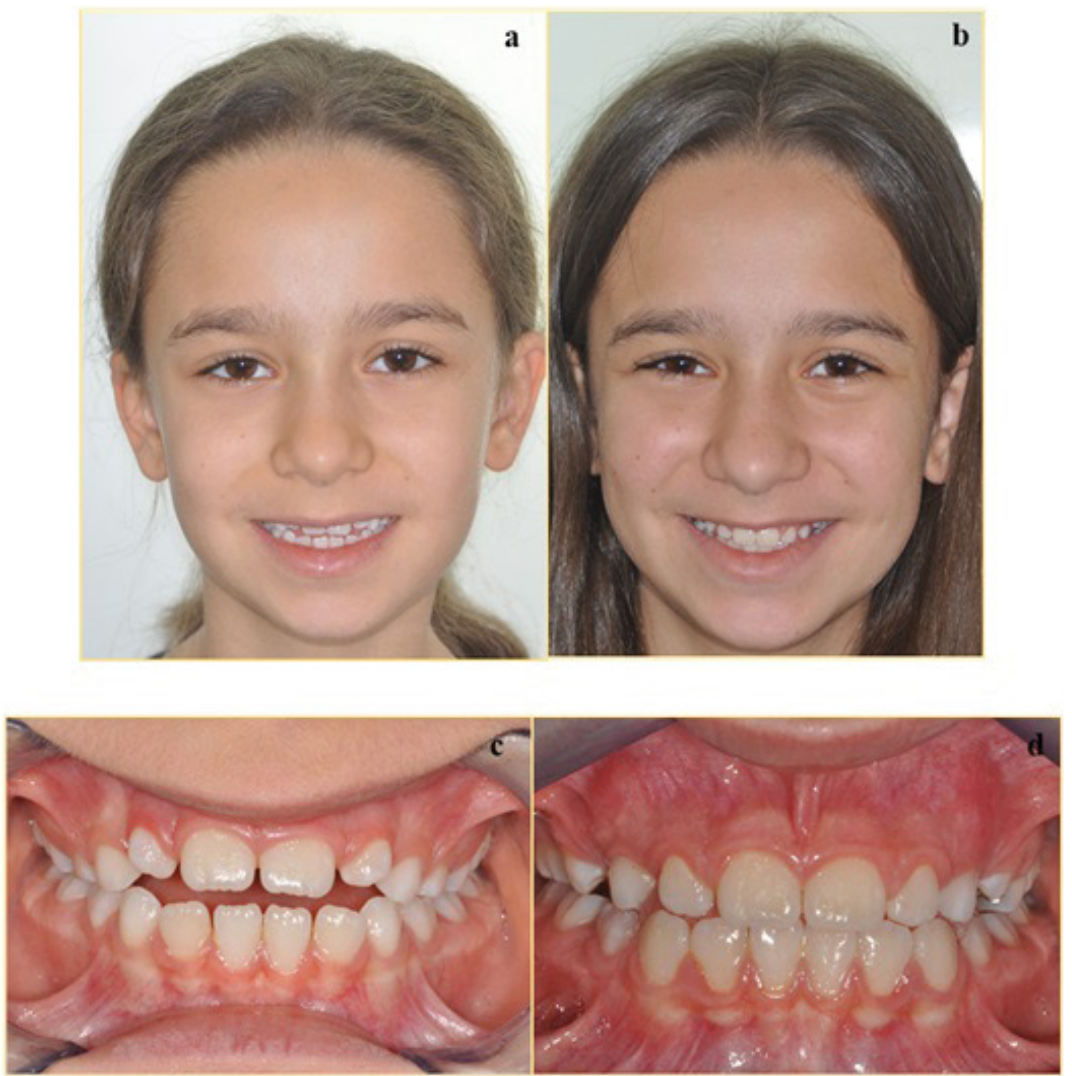

Figure 1: $(a, b)$ Extraoral images before and after orthodontic treatment; $(c, d)$ Intraoral images before and after orthodontic treatment.

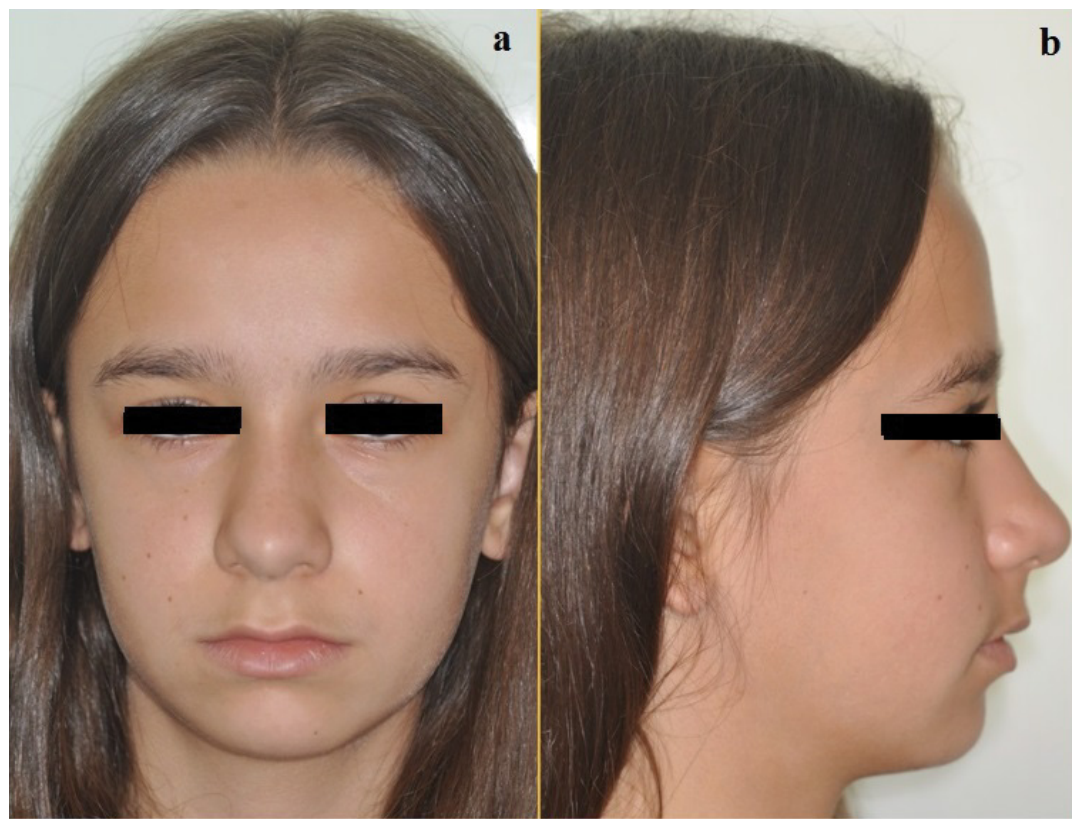

Figure 2: (a) Extraoral image illustrating mild facial asymmetry and dropping of the inferior border of upper right eye; (b) Hypertrichosis and several nevi from light to dark brown were evident on right cheek. 
family. The patient presented with a skeletal CI I malocclusion. The intra-oral examination revealed that there was anterior open bite and tongue thrust (Figure 1c). Extra-orally, mild facial asymmetry and dropping of the inferior border of upper right eye were observed. Hypertrichosis and several nevi from light to dark brown were evident on right cheek (Figure $2 a$ and Figure $2 b$ ). Intraoral examination showed that there was a deciduous carious tooth and missing $2^{\text {nd }}$ premolar. Radiological examination showed that there was a deciduous carious tooth and missing $2^{\text {nd }}$ premolar involving the right posterior maxilla along with irregular trabeculation of the bone. Panoramic and intraoral radiography taken at the time of examination showed that the affected maxillary posterior bone showed altered, irregular and vertically oriented trabeculae. Hypodontia of the permanent maxillary right second premolar along with resorbed and carious deciduous molars were also detected (Figure 3a and Figure 3b). Axial CBCT scans indicated slightly enlarged right maxillary posterior alveolar ridge with irregular bone when compared to left side alveolar ridge (Figure 3c). Fluid retention in maxillary sinus along with nasal airway obstruction was easily detected (Figure $3 d)$.

Panoramic radiography of the patient taken 1 year after the beginning of the treatment shows the affect- ed region (Figure 4a). Intra-orally, the edentulous right maxillary alveolar process appeared slightly larger than the left 1 month after extraction of deciduous molars (Figure 4b). Biopsy obtained from the patient showed fibrous connective tissue in the interstitial space between osseous trabeculae. Hard tissue demonstrated irregular lamellar trabecular bone. Some trabeculea were seen as round shaped sementoid tissue similar to fibro osseous lesions (Figure 4c, Figure 4d and Figure 4e). Besides, distrophic calcifications in the pulp were also detected (Figure 4f). Regional odontodysplasia, hemifacial hyperplasia, and monostatic fibrous dysplasia were all considered for differential diagnosis. On the basis of the clinical, radiographic and histologic findings, a diagnosis of HD-SOD was made.

Right IV, III, and left III, IV were extracted. An openbite activator (Functional Orthodontic Therapy) was applied for 12 months and a swallowing exercise was planned simultaneously. Then the appliance was worn at night as a retention appliance for almost 6 months. The open-bite activator had posterior acrylic bite blocks in order to prevent posterior teeth from coming out [14]. The appliance that did not contact the incisal edges of the maxillary and mandibular incisors allowed extrusion of incisors. During 1 year of follow-up, the condition was non-progressive.

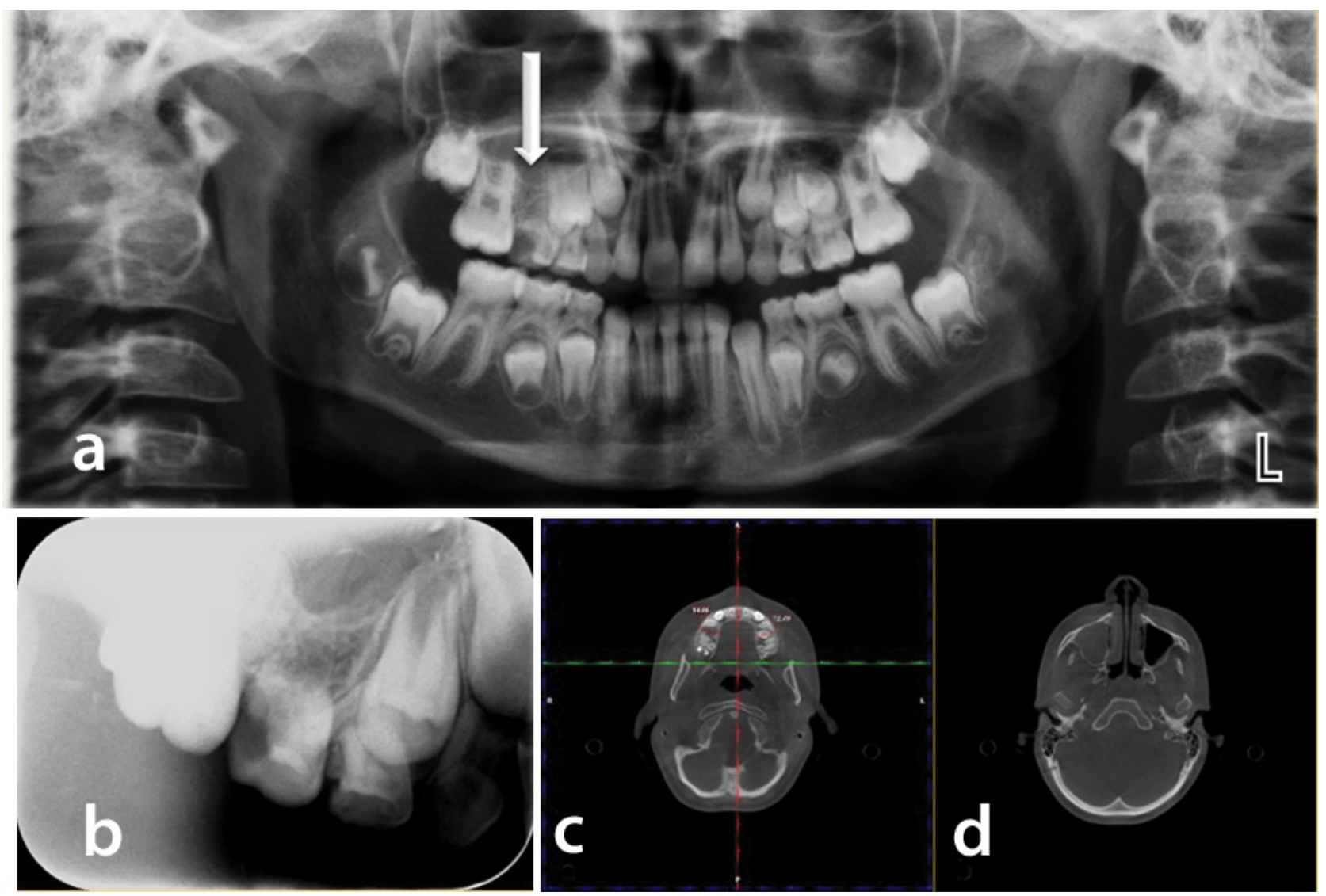

Figure 3: $(a, b)$ Panoramic and periapical radiographic images taken at the time of examination showed that the affected maxillary posterior bone showed altered, irregular and vertically oriented trabeculae. Periapical radiographic image showed hypodontia of the permanent maxillary right second premolar along with resorbed and carious deciduous molars; (c) Axial CBCT scans indicated slightly enlarged right maxillary posterior alveolar ridge with irregular bone when compared to left side alveolar ridge; (d) Fluid retention in maxillary sinus along with nasal airway obstruction was easily detected. 


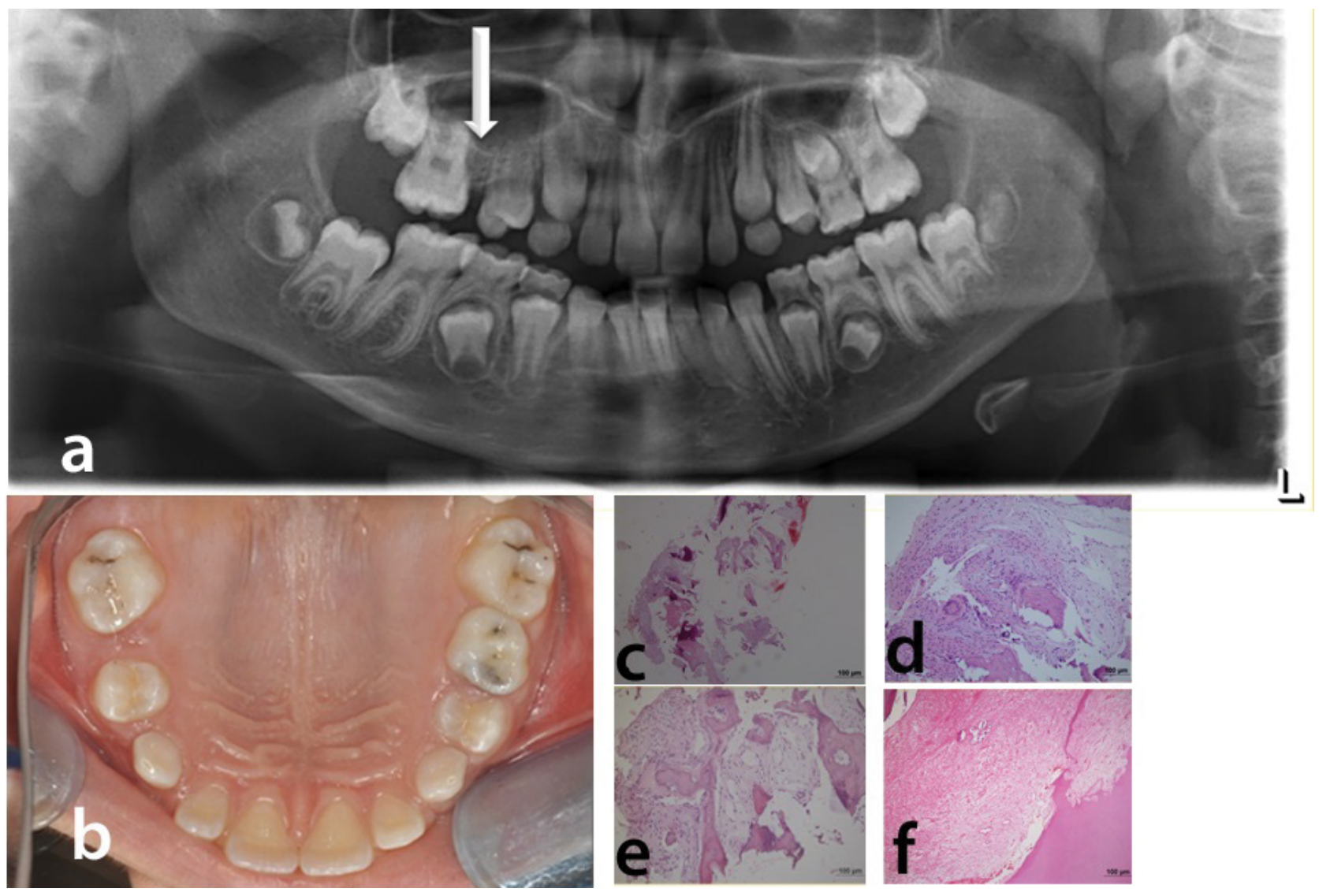

Figure 4: (a) Recent panoramic radiography of the patient taken 1 year after the beginning of the treatment. White arrow shows the affected region; (b) Intraoral photography of the patient; (c) (HE staining x40); (d,e) (HE staining x100): Fibrous connective tissue in the interstitial space between osseous trabeculae. Hard tissue demonstrated irregular lamellar trabecular bone; (f) (HE staining $\times 100)$ : Distrophic calcifications in the pulp tissue.

\section{Discussion}

A review of the literature was completed by searching PubMed for cases published in English before January 2020. Up until now 65 cases of HD/SOD were reported except for the present case. Clinical and radiographic findings in HD-SOD of 65 cases diagnosed between 1987 and 2020 and the present case is presented in Table 1. Although the etiology is unclear, systemic or endocrine aberration, post-zygotic mutation of bone and skin, and viral or bacterial infection along the branches of the maxillary division of the trigeminal nerve are among the possible causes of the syndrome [1-31]. The clinical and radiological findings accompanying the syndrome represent a large spectrum of variations among individuals. We have found that the lesion is discovered mainly in the $1^{\text {st }}$ decade of life. The maxillary alveolar process enlargement involving the gingiva, the bone, or both in all cases along with facial asymmetry were constant findings. Facial asymmetry was usually mild and not stated in most cases. Since facial asymmetry is non-progressive, recontouring osteotomy is not necessary for most patients. The main objective should be to maintain the primary teeth and to enhance eruption of the permanent molars in order to restore occlusion [1-31]. In the case presented here, an open bite activator was applied after extraction and during 1 year of follow-up, the condition was non-progressive. In case of severe facial asymmetry cases appropriate functional orthopedic or surgical treatment by conducting ortognathic distraction may be applied. In addition, tooth eruption guidance and unilateral expansion may be important tools for the treatment of this disorder. Missing teeth should be replaced by the combined efforts of prosthodontist, surgeon and orthodontist.

The age at diagnosis ranged between 2 and 45 years. There were 41 male $(63 \%)$ and 24 female (37\%) patients and an almost equal distribution for right (32 of 62) and left (32 of 62) maxilla. In a unique case of a SOD it was unclear from the radiographic and surgical images assessed whether the patient demonstrated buccolingual bony expansion with radiographic changes but the authors were the first to report SOD along midline. This case was characterized with pre-maxillary enlargement and abnormal pattern of eruption of anterior maxillary permanent teeth [26]. Twenty-five of 65 cases described showed ipsilateral cutaneous changes, including hypertrichosis, hyperpigmentation, hypopigmentation, erythema, lesions, ectopic eyelashes, Becker nevus, cleft lip, facial depression, and commissural lip pit. Distribution of clinical findings in hemimaxillofacial dysplasia/segmental odontomaxillary dysplasia of 65 cases diagnosed between 1987 and 2020 is given in Table 2 . 


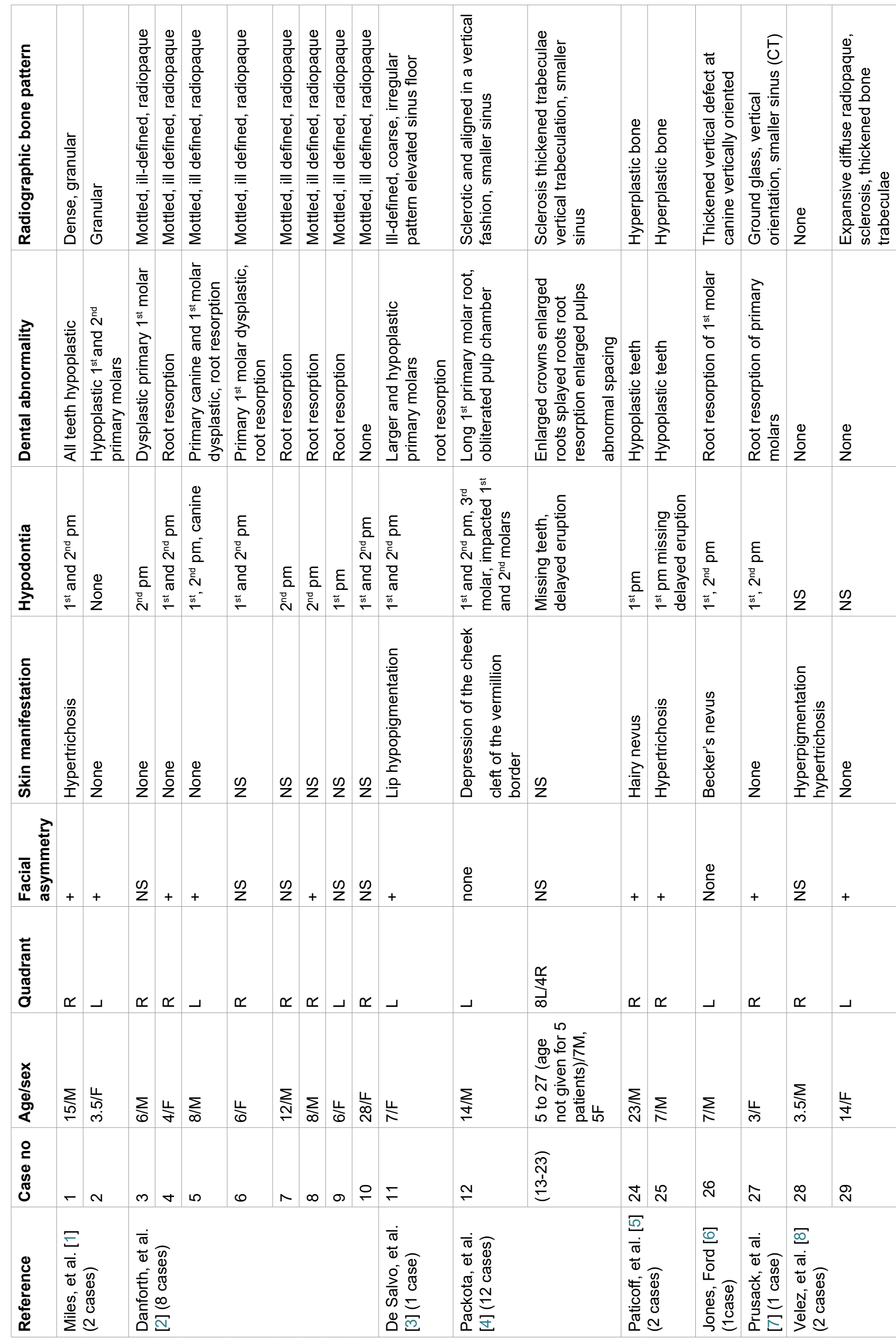




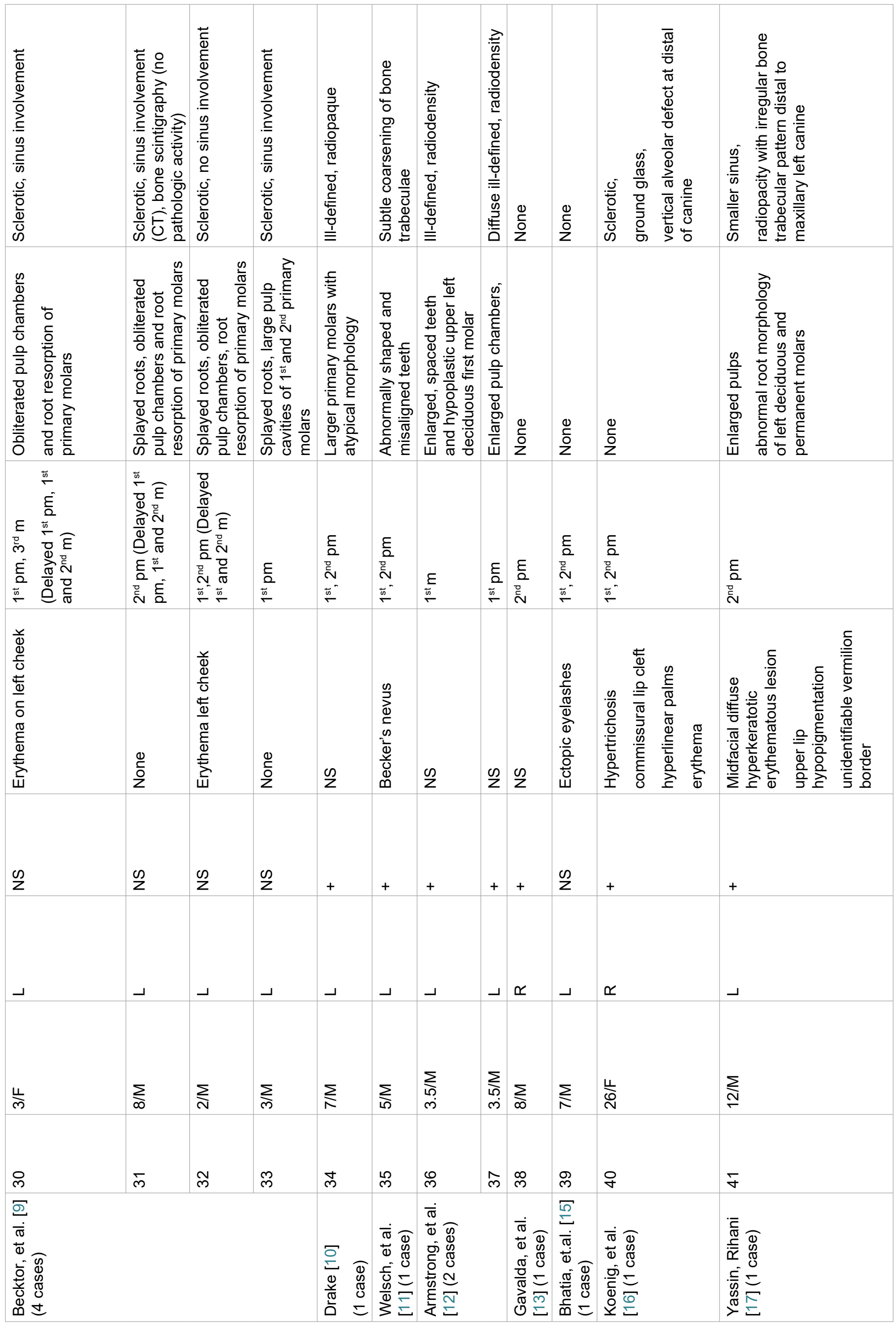




\begin{tabular}{|c|c|c|c|c|c|c|c|c|c|c|c|c|}
\hline 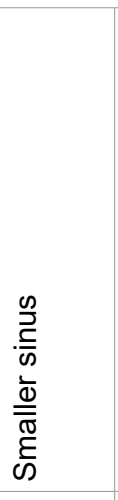 & 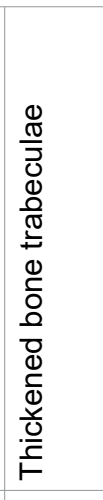 & 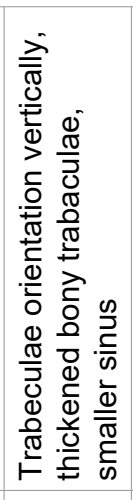 & $\begin{array}{l}0 \\
2 \\
2 \\
2\end{array}$ & $\begin{array}{l}0 \\
\text { ò } \\
z\end{array}$ & 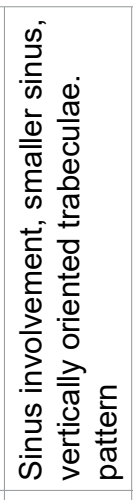 & 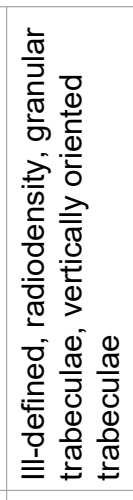 & 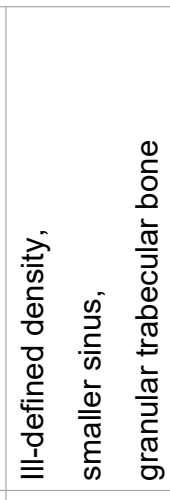 & 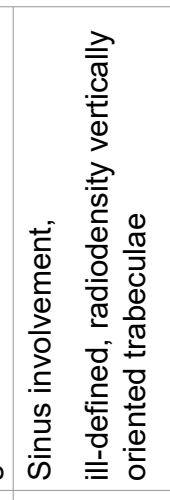 & 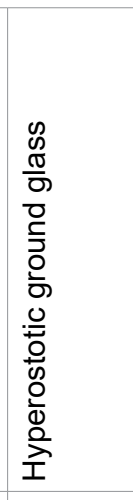 & 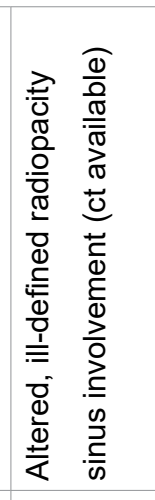 & 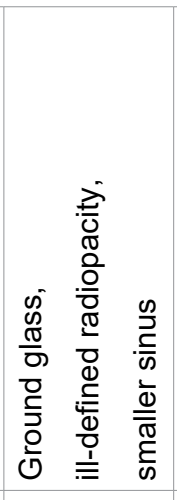 & 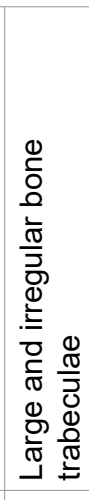 \\
\hline $\begin{array}{l}0 \\
\text { ¿ } \\
z\end{array}$ & $\begin{array}{l}0 \\
\text { ¿ } \\
z\end{array}$ & $\begin{array}{l}0 \\
\text { ¿ } \\
z\end{array}$ & $\begin{array}{l}0 \\
\text { ò } \\
z\end{array}$ & 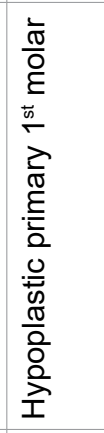 & 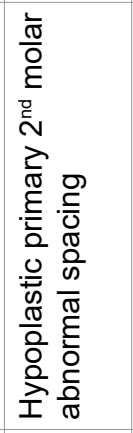 & 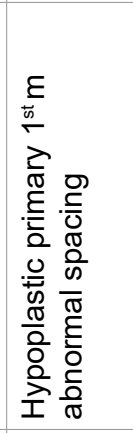 & 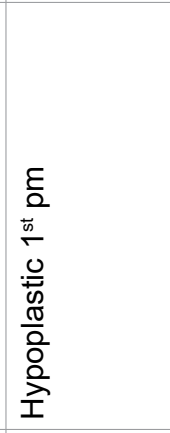 & 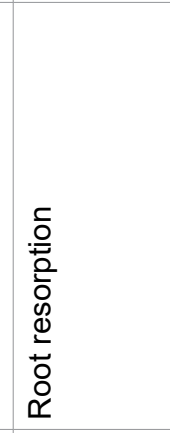 & 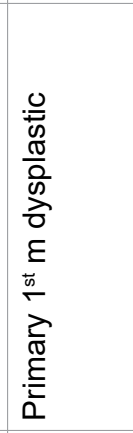 & 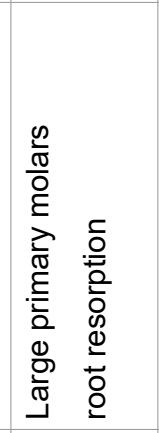 & $\begin{array}{l}0 \\
\stackrel{0}{0} \\
z\end{array}$ & $\begin{array}{l}0 \\
\text { ¿ } \\
z\end{array}$ \\
\hline 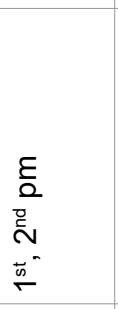 & $\begin{array}{l}0 \\
\text { ¿ } \\
z\end{array}$ & 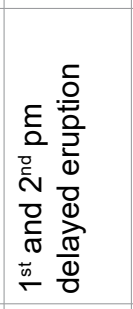 & 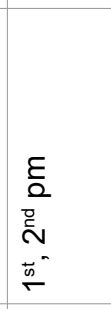 & 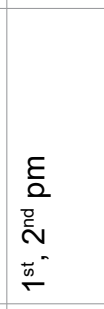 & $\begin{array}{l}0 \\
\frac{0}{2} \\
z\end{array}$ & 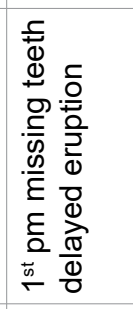 & 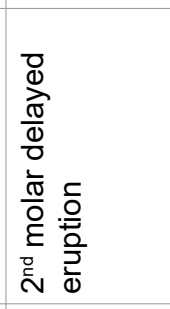 & 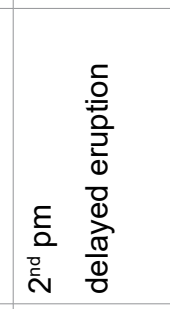 & I & 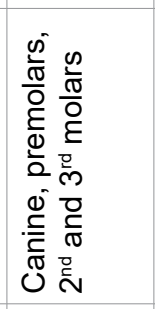 & 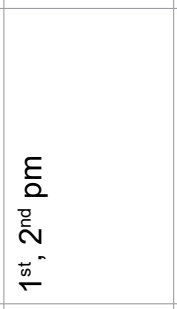 & 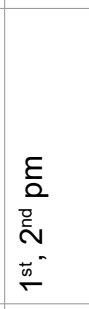 \\
\hline 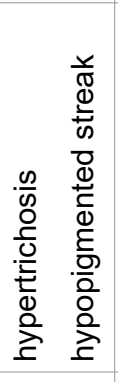 & $\begin{array}{l} \\
0 \\
\text { Oे } \\
2\end{array}$ & 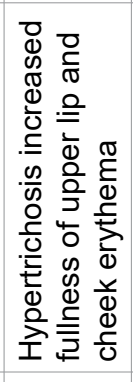 & 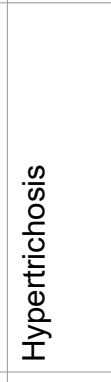 & $\begin{array}{l}0 \\
\stackrel{0}{2} \\
z\end{array}$ & $\begin{array}{l}0 \\
\text { ô } \\
z\end{array}$ & $\begin{array}{l}0 \\
\stackrel{0}{2} \\
z\end{array}$ & $\begin{array}{l}0 \\
\text { ò } \\
z\end{array}$ & $\begin{array}{l}0 \\
\stackrel{0}{2} \\
z\end{array}$ & 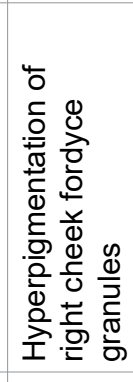 & 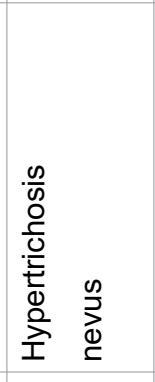 & 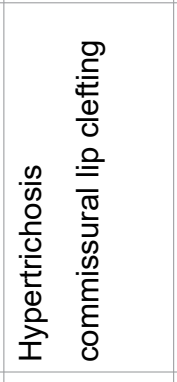 & , \\
\hline+ & $\stackrel{0}{Z}$ & + & + & $\begin{array}{l}0 \\
\text { ò } \\
z\end{array}$ & $\begin{array}{l}0 \\
\text { ¿̇ } \\
z\end{array}$ & $\begin{array}{l}0 \\
\text { ¿̇ }\end{array}$ & $\begin{array}{l}0 \\
\text { ò } \\
z\end{array}$ & $\begin{array}{l}0 \\
\stackrel{2}{0} \\
z\end{array}$ & 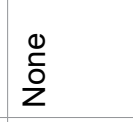 & $\begin{array}{l}0 \\
\frac{0}{2} \\
z\end{array}$ & + & + \\
\hline$\propto$ & - & \lrcorner & \lrcorner & $\simeq$ & $\propto$ & $\propto$ & $\simeq$ & $\simeq$ & $\simeq$ & $\simeq$ & $\simeq$ & $\propto$ \\
\hline$\underset{\mathrm{J}}{\mathrm{U}}$ & $\underset{f}{\stackrel{U}{\sigma}}$ & $\sum_{\delta}$ & $\underset{⿱}{\stackrel{L}{\sim}}$ & $\stackrel{u}{\vec{\sigma}}$ & $\underset{\downarrow}{\lessgtr}$ & 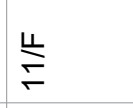 & $\sum_{j}$ & $\sum_{\infty}$ & $\sum_{i \infty}$ & $\underset{\underset{N}{N}}{\sum}$ & $\underset{\mathrm{N}}{\stackrel{\mathrm{N}}{\mathrm{N}}}$ & $\underset{⿱}{\stackrel{\Sigma}{N}}$ \\
\hline$\stackrel{\mathcal{F}}{\mathcal{F}}$ & 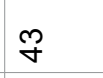 & ষ & $\stackrel{\circ}{q}$ & $\mathscr{q}$ & f & $\stackrel{\infty}{\sim}$ & \& & 오 & is & ธิ & బొ & L5 \\
\hline 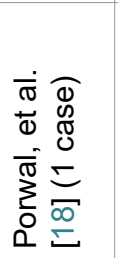 & 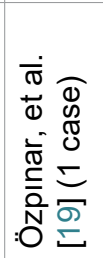 & 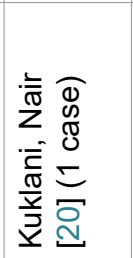 & 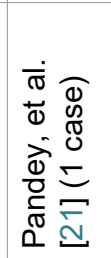 & 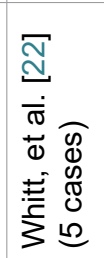 & & & & & 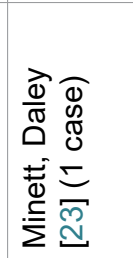 & 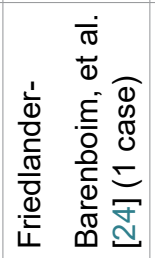 & 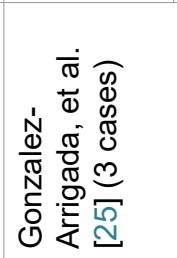 & \\
\hline
\end{tabular}




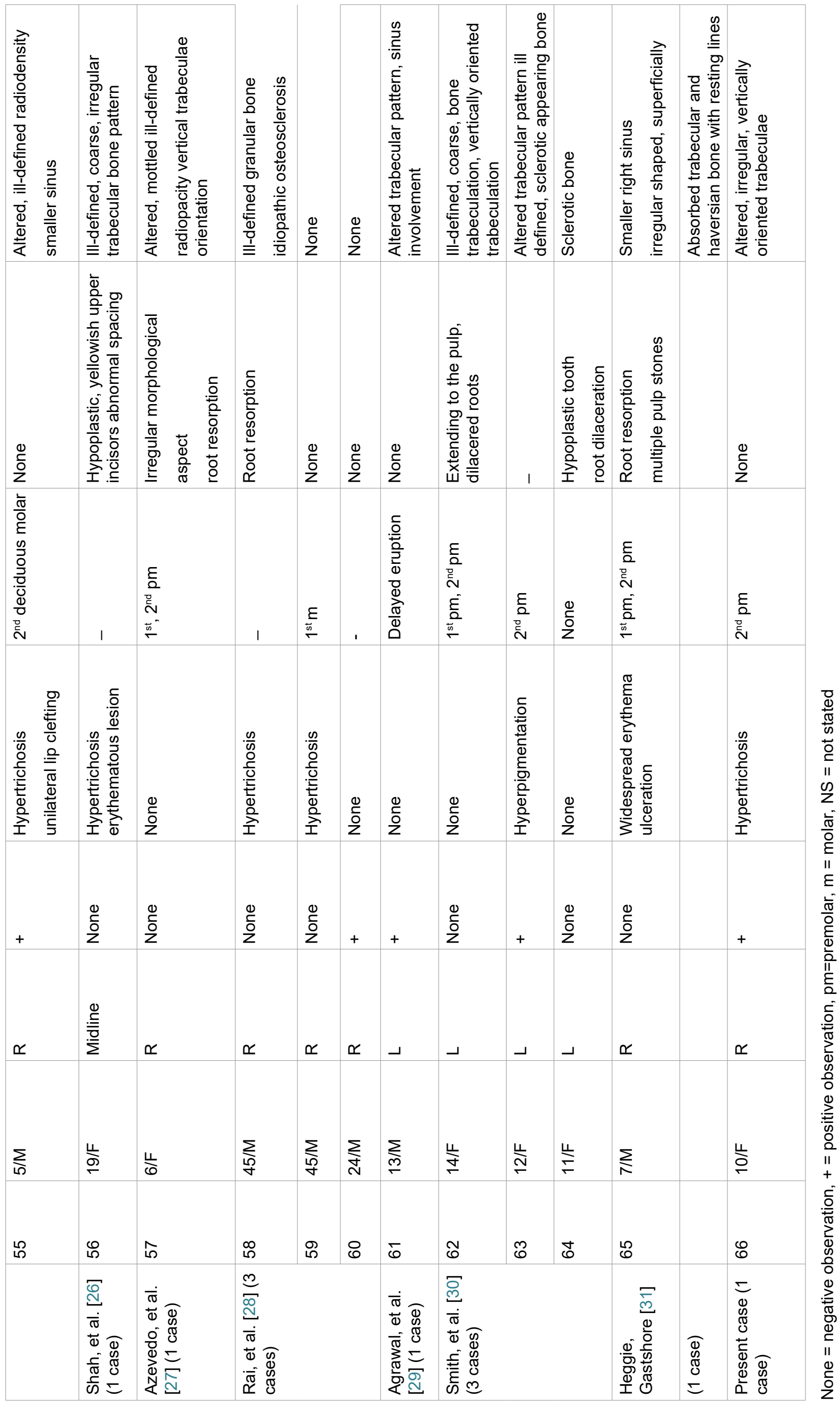


Radiologically, in most cases the first premolar or both permanent premolars were missing. Delayed eruption, displaced teeth, root resorption, hypoplastic teeth and enlarged pulps were among the most reported dental abnormalities. Bone pattern was generally termed as vertically oriented, sclerotic, ill-defined, dense and granular radiopacity in some cases extending in to the maxillary sinus making it depicted smaller than the opposite side in the radiological images [1-31]. We defined the radiographic appearance as altered, irregular and vertically oriented trabeculae. Our case report was radiologically unique. On axial sections of $C B C T$, rather than extensive alveolar enlargement mildly enlarged right maxillary posterior alveolar ridge was observed,

Table 2: Distribution of clinical findings in hemimaxillofacial dysplasia/segmental odontomaxillary dysplasia of 65 cases diagnosed between 1987 and 2020.

\begin{tabular}{|c|c|c|}
\hline Clinical findings & Number & Percentage \\
\hline \multicolumn{3}{|l|}{ Age $(n=60)$} \\
\hline $1-10$ & 33 & $54 \%$ \\
\hline $10-20$ & 18 & $31 \%$ \\
\hline $20-30$ & 6 & $10 \%$ \\
\hline $40-50$ & 3 & $5 \%$ \\
\hline Unknown & 5 & \\
\hline \multicolumn{3}{|l|}{ Gender $(n=66)$} \\
\hline Male & 42 & $63.5 \%$ \\
\hline Female & 23 & $37 \%$ \\
\hline Unknown & - & \\
\hline \multicolumn{3}{|l|}{ Quadrant $(n=66)$} \\
\hline Left & 32 & $48.5 \%$ \\
\hline Right & 32 & $50 \%$ \\
\hline Midline & 1 & $1 \%$ \\
\hline \multicolumn{3}{|c|}{ Facial asymmetry $(n=41)$} \\
\hline Yes & 25 & $65 \%$ \\
\hline No & 15 & $36.5 \%$ \\
\hline Unknown & 25 & \\
\hline \multicolumn{3}{|c|}{ Skin manifestations $(n=45)$} \\
\hline Yes & 24 & $55.5 \%$ \\
\hline No & 20 & $44.5 \%$ \\
\hline Unknown & 21 & \\
\hline
\end{tabular}

therefore; this case might be considered as a mild form of the disorder. Rather than taking occlusal radiographs the mediolateral expansion of the alveolar process and extent of the enlargement was accurately determined by $C B C T$ in three dimensions. CBCT imaging also indicated fluid retention in maxillary sinus along with nasal airway obstruction. Sinus involvement was reported in approximately one half of the previous cases. In our case, СBCT examination of the patient provided more accurate data compared to panoramic and periapical radiographs. CBCT imaging of HD cases are encouraged to understand the full extent of the maxillofacial involvement in this disorder [1-31]. Radiological findings in hemimaxillofacial dysplasia/segmental odontomaxillary dysplasia of 65 cases diagnosed between 1987 and 2020 are shown in Table 3.

As unilateral enlargement of the alveolar process was not prominent in the case reported here the diagnosis could not be made without the assessment of skin manifestations. Hypertrichosis and nevi were observed along with the dropping of the right eye and right vermillion border in the presented patient. Hypertrichosis has been previously reported in male patients mostly. In most patients, it is possible that skin lesions were unrecognizable or ignored because of the dento-maxillary involvement. Hypertrichosis, Becker's nevus, nevus, erythema of the cheek, erythematous lesions, lip hypopigmentation, cheek hyperpigmentation, depression of the cheek, cleft of the vermillion border, and lip clefting were among commonly diagnosed skin manifestations. Some patients had different manifestations simultaneously [1-31].

Regional odontodysplasia, hemifacial hyperplasia, and monostatic fibrous dysplasia were all considered for differential diagnosis of HD/SOD. In regional odontodysplasia affected teeth may be unerupted, however; there is no association with alteration of alveolar bone. Hemifacial hyperplasia is not associated with coarse vertically oriented trabeculae. Fibrous dysplasia is not associated with skin manifestations and unerupted teeth [24].

In our notion, the reported cases are insufficient to completely describe HD/SOD. New cases should include clinical, radiographic, histologic findings, follow-up re-

Table 3: Radiological findings in hemimaxillofacial dysplasia/segmental odontomaxillary dysplasia of 65 cases diagnosed between 1987 and 2020.

\begin{tabular}{|c|c|c|c|}
\hline Hypodontia & Dental abnormality & Bone pattern & Sinus involvement \\
\hline 1 premolar & Displaced-separated & Sclerosis/sclerotic & \multirow[t]{8}{*}{ Smaller sinus } \\
\hline 2 premolars & Root resorption & Thickened trabeculae & \\
\hline \multirow[t]{6}{*}{ Delayed eruption } & Enlarged teeth & Vertical trabeculation & \\
\hline & Hypoplastic teeth & III-defined opacity & \\
\hline & Enlarged pulps & Dense and granular & \\
\hline & Splayed roots & Hyperplastic & \\
\hline & \multirow[t]{2}{*}{ Obliterated pulp chambers } & Ground glass & \\
\hline & & Hyperostotic & \\
\hline
\end{tabular}


ports and treatment protocols to improve dentist and parent information regarding HD/SOD.

\section{Conclusion}

$\mathrm{HD} / \mathrm{SOD}$ is a rare and unusual condition affecting the maxilla and associated structures. Early recognition of $\mathrm{HD} / \mathrm{SOD}$ also requires appropriate referrals to specialists and interdisciplinary team approach, thus patients with HD/SOD can gain access to specialist dental care, including orthodontics, prosthodontics, and oral surgery.

\section{References}

1. Miles DA, Lovas JL, Cohen MM (1987) Hemimaxillofacial dysplasia: A newly recognized disorder of facial asymmetry, hypertrichosis of the facial skin, unilateral enlargement of the maxilla, and hypoplastic teeth in two patients. Oral Surg Oral Med Oral Pathol 64: 445-448.

2. Danforth RA, Melrose RJ, Abrams AM, Handlers JP (1990) Segmental odontomaxillary dysplasia. Report of eight cases and comparison with hemimaxillofacial dysplasia. Oral Surg Oral Med Oral Pathol 70: 81-85.

3. De Salvo MS, Copete MA, Riesenberger RE, Cleveland DB, Chen SY (1996) Segmental odontomaxillay dysplasia (hemimaxillofacial dysplasia): Case report. Pediatr Dent 18: 154-156.

4. Packota GV, Pharoah MJ, Petrikowski CG (1996) Radiographic features of segmental odontomaxillary dysplasia: $A$ study of 12 cases. OSOMOPORE 82: 577-584.

5. Paticoff K, Marion RW, Shprintzen RJ, Shanske AL, Eisig SB (1997) Hemimaxillofacial dysplasia: A report of two new cases and further delineation of the disorder. Oral Surg Oral Med Oral Pathol Oral Radiol Endod 83: 484-488.

6. Jones AC, Ford MJ (1999) Simultaneous occurrence of segmental odontomaxillary dysplasia and Becker's nevus. J Oral Maxillofac Surg 57: 1251-1254.

7. Prusack N, Pringle G, Scotti V, Chen SY (2000) Segmental odontomaxillary dysplasia: A case report and review of the literature. Oral Surg Oral Med Oral Pathol Oral Radiol Endod 90: 483-488.

8. Velez I, Vedrenne D, Cralle P, Yap S (2002) Segmental odontomaxillary dysplasia. Report of two cases and review of the literature. Todays FDA 14: 20-21.

9. Becktor KB, Reibel J, Vedel B, Kjaer I (2002) Segmental odontomaxillary dysplasia: Clinical, radiological and histological aspects of four cases. Oral Dis 8: 106-110.

10. Drake DL (2003) Segmental odontomaxillary dysplasia: An unusual orthodontic challenge. Am J Orthod Dentofacial Orthop 123: 84-86.

11. Welsch MJ, Stein SL (2004) A syndrome of hemimaxillary enlargement, asymmetry of the face, tooth abnormalities, and skin findings (HATS). Pediatr Dermatol 21: 448-451.

12. Armstrong C, Napier SS, Boyd RC, Gregg TA (2004) Histopathology of the teeth in segmental odontomaxillary dysplasia: New findings. J Oral Pathol Med 33: 246-248.

13. Gavalda C (2004) Segmental odontomaxillary dysplasia. Med Oral 9: 181.

14. Defraia E, Marinelli A, Baroni G, Franchi L, Baccetti T (2005) Early orthodontic treatment of skeletal open-bite malocclusion with the open-bite bionator: A cephalometric study. Am J Orthod Dentofacial Orthop 132: 595-598.
15. Bhatia SK, Drage N, Cronin AJ, Hunter ML (2008) Case report: Segmental odontomaxillary dysplasia-a rare disorder. Eur Arch Paediatr Dent 9: 245-248.

16. Koenig LJ, Lynch DP, Yancey KB (2008) Segmental odontomaxillary dysplasia presenting with facial hypertrichosis, commissural lip clefting, and hyperlinear palms. Pediatr Dermatol 25: 491-492.

17. Yassin OM, Rihani FB (2008) Combined cutaneous findings with segmental odontomaxillary dysplasia: Review of the literature and proposal of a new clinical classification. Int Med Case Rep J 1: 7-11.

18. Porwal R, Ousterhout DK, Hoffman WY, Vargervik K, Oberoi S (2008) Hemimaxillofacial dysplasia: A variable presentation. J Craniofac Surg 19: 1554-1557.

19. Ozpinar B, Gökçe B, Uzel G, Cömlekoglu ME (2009) Prosthetic rehabilitation of segmental odontomaxillary dysplasia: Seven-year follow-up. Cleft Palate Craniofac J 46: 103-107.

20. Kuklani RM, Nair MK (2010) Segmental odontomaxillary dysplasia: Review of the literature and case report. Int J Dent.

21. Pandey S, Pai KM, Nayak AG, Vineetha R (2011) Unilateral segmental odontomaxillary hypoplasia: An unusual case report. Imaging Sci Dent 41: 39-42.

22. Whitt JC, Rokos JW, Dunlap CL, Barker BF (2011) Segmental odontomaxillary dysplasia: Report of a series of 5 cases with long-term follow-up. Oral Surg Oral Med Oral Pathol Oral Radiol Endod 112: 29-47.

23. Minett CP, Daley TD (2012) Hemimaxillofacial dysplasia (segmental odontomaxillary dysplasia): Case study with 11 years of follow-up from primary to adult dentition. $J$ Oral Maxillofac Surg 70: 1183-1191.

24. Friedlander-Barenboim S, Kamburoglu K, Kaffe I (2012) Clinical and radiological presentation of hemimaxillofacial dysplasia/segmental odontomaxillary dysplasia: Critical analysis and report of a case. Oral Surg Oral Med Oral Pathol Oral Radiol 113: 268-273.

25. Gonzalez-Arriagada, Vargas PA, Fuentes-Cortés R, Nasi-Toso MA, Lopes MA (2012) Segmental odontomaxillary dysplasia: Report of 3 cases and literature review. Head and Neck Pathol 6: 171-177.

26. Ajaz Shah, Suhail Latoo, Irshad Ahmed, Altaf H Malik, Shahid Hassan, et al. (2012) Midline segmental odontomaxillary dysplasia. Ann Maxillofac Surg 2: 185-189.

27. Azevedo RS, da Silveira LJ, Moliterno LF, Miranda ÁM, de Almeida OP, et al. (2013) Segmental odontomaxillary dysplasia: Report of a case emphasizing histopathological, immunohistochemical and scanning electron microscopic features. J Oral Sci 55: 259-262.

28. Rai S, Malik R, Panjwani S, Misra D, Verma S (2014) Unilateral segmental odontomaxillary dysplasia: A rare entity of 3 cases and review. Indian J Dent Res 25: 102-106.

29. Agrawal A, Daniel J, Vijeev V (2014) Segmental odontomaxillary dysplasia. J Indian Soc Pedod Prev Dent 32: 83-86.

30. Smith MH, Cohen DM, Katz J, Bhattacharyya I, Islam NM (2018) Segmental odontomaxillary dysplasia: An underrecognized entity. J Am Dent Assoc 149: 153-162.

31. Heggie C, Gartshore L (2020) Diagnosis, management and follow-up of a rare regional developmental disorder: Segmental odontomaxillary dysplasia. J Dent Child 87: 39-43.
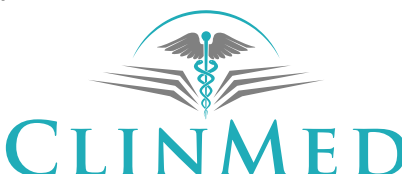

INTERNATIONAL LIBRARY 